Escuela de Ciencias Sociales y Humanidades, UNED, C.R. https://revistas.uned.ac.cr/index.php/espiga ISSN: 1409-4002 • e-ISSN: 2215-454X

\title{
El humanismo marxista
}

Walter Calvo-Gómez

(iD https://orcid.org/0000-0003-3697-1215

Recibido: 28 de marzo, 2019 - Aceptado: 31 de agosto, 2019

\section{RESUMEN}

El artículo tiene como principal objetivo sopesar acerca del proceso evolutivo por el cual ha transitado el humanismo en su devenir histórico, además de demostrar el salto paradigmático surgido bajo la visión del humanismo marxista. Se recurre al enfoque cualitativo e histórico con el fin de explicar tres elementos metodológicos del trabajo: primero, identificar la génesis del humanismo en el desenvolvimiento de la naturaleza y existencia de la humanidad; segundo, los tipos de humanismo según el momento histórico, sin olvidar movimientos como la Ilustración, el humanismo liberal francés y alemán del siglo XVIII; y tercero, análisis del humanismo marxista como el paradigma emancipador del ser humano. Se problematiza sobre el humanismo marxista, puesto que Marx plantea, por primera vez en la historia de la humanidad, cómo en las relaciones sociales y de producción del sistema capitalista se incuba la enajenación del ser humano. Se procedió a un análisis hermenéutico para articular la dimensión histórica, cultural, socio-política y contextual de diversos estudios publicados sobre el tema, con la intensión de demostrar los aportes de Marx y del marxismo al discurso del humanismo.

Palabras clave: Historia, antihumanismo, sociedad, alienación.

\section{Formato de citación según APA}

Calvo Gómez, W. (2019). El humanismo marxista. Revista Espiga, 18 (38), 226-244.

Formato de citación según Chicago-Deusto

Calvo Gómez, Walter (2019). «El humanismo marxista». Revista Espiga 18, n. ${ }^{\circ} 38$ (juliodiciembre, 2019): 226-244.

* Bachillerato en Historia, Universidad Nacional de Costa Rica (UNA). Licenciatura en Docencia en Historia, Universidad Estatal a Distancia (UNED), Costa Rica. Maestría en Ciencias de la Educación con énfasis en Docencia, Universidad Americana (UAM), Costa Rica. Egresado de la Maestría en Humanismo, Sociedad y Ambiente, Centro de Estudios Generales (CEG, UNA). Académico de Historia de la Cultura de la Universidad Técnica Nacional (UTN), Costa Rica. Correos: waltercalvog@gmail.com, wcalvo@utn.ac.cr 


\section{Introducción}

Este texto reflexiona concretamente sobre el humanismo marxista, pero su estudio rebasa su ámbito de acción, puesto que referirse al humanismo conlleva a la problematización originada desde la contextualidad y conceptualidad dentro de su propia diversidad. De ahí que se siga una metodología que justifique, en primera instancia, un acercamiento a la génesis del humanismo, así como precisar un acercamiento al término. Al mismo tiempo, reseñar las diferentes corrientes humanistas, partiendo de la visión greco-latina para transitar por el pensamiento materialista e idealista del siglo XVIII, el humanismo liberal y el materialismo histórico-revolucionario del siglo XIX y su proyección histórica en el XX. Estas acotaciones conducen a la siguiente meditación:

Alguien ha dicho con mucha propiedad que el humanismo es todo un proceso espiritual, intelectual e histórico que va indivisiblemente ligado a una época, a un pueblo, cuya contribución se ha hecho con letras o con sangre a fin de que el hombre sea más hombre y su vida más digna y más humana. Es indiscutible que el humanismo ha logrado en tal sentido desde la época antigua hasta el momento presente- liberar al hombre en gran medida de su animalidad tosca, para dotarlo de elementos espirituales con los cuales pueda sentirse orgulloso de su condición ${ }^{1}$.

Es necesario recalcar que el presente escrito busca reconstruir con visión histórica el pensamiento humanista, con sus diversos representantes y matices, así mismo ubicar el pensamiento marxista y su influencia en la sociedad.

Metodológicamente es imprescindible lograr una definición de lo que se entiende por humanismo. Es posible que no se logre con precisión debido a la misma trayectoria histórica, puesto que se han construido diversas visiones desde lo político, lo social, lo económico y en el ámbito general de la cultura, en lo referente a la arquitectura y semántica de la existencia de un humanismo real, visto como construcción social. «El hombre -dice Marx- debe tomar conciencia de la realidad para aplicar su acción en un esfuerzo transformador; el medio social y natural debe ser modelado de tal modo que favorezca un verdadero desarrollo humano» ${ }^{2}$.

Apoyándose en Carta sobre el humanismo, de M. Heidegger, Salvador Ignacio Rus es claro cuando señala que:

El término humanismo asigna la especial, singular, consideración que ha tenido el hombre en un sistema de pensamiento. Es humanista cualquier doctrina o teoría que intenta explicar la significación del hombre dentro del universo, el lugar que corresponde al hombre mismo y a sus valores, $\mathrm{y}$, en función de dichos valores, formula un ideal de hombre ${ }^{3}$.

1. Jorge Rolando Molina González, «Consideraciones generales sobre diversas concepciones históricas del humanismo», Revista Estudios, n. ${ }^{\circ} 8$ (1989): 7-8, acceso: 22 de noviembre, 2019, https://dialnet.unirioja.es/servlet/ articulo? codigo $=6135730 \mathrm{pdf}$

2. Emilio Serrano Villafañe, «Cristianismo y Marxismo», Revista de Estudios Políticos, n. ${ }^{\circ}$ 206-207 (1976): 140, acceso: 22 de noviembre, 2019, https://dialnet.unirioja.es/descarga/articulo/1704476.pdf

3. Salvador Ignacio Rus, «La aparición del humanismo en Grecia y la aportación de Protágoras», Revista de fundamentación de las Instituciones Jurídicas y de Derechos Humanos (1985): 123-161, acceso: 23 de noviembre 2019, http://dadun.unav.edu/bitstream/10171/12535/1/PD_13_04.pdf 
En términos generales, el humanismo ha sido empleado para denominar toda corriente que defienda como principio fundamental el respeto y la dignidad de la persona. La palabra tiene una significación histórica, puesto que el humanismo es un fenómeno histórico cuyo contenido e interpretación específicos han cambiado según las circunstancias del desarrollo social, ya que este se repite una y otra vez a lo largo de la historia de la humanidad. En este sentido, los aportes de Baraona y Mora ${ }^{4}$, en su obra Hacia una epistemología del Nuevo Humanismo, definen el término en sentido lato como toda representación simbólica desarrollada a lo largo de la historia que intenta definir lo esencial dentro de la naturaleza humana. En su sentido estricto, es un conjunto de discursos explícitos y organizados sobre la esencia humana y que han aparecido por etapas desde el siglo V a. n. e., hasta estos días, con muchas vertientes y orientaciones diferentes ${ }^{5}$.

Existen muchos y diversos enfoques del significado real de humanismo, pero para ser consecuentes con la historia de la especie humana, se debe interpretar cada uno en su propio contexto, de manera que facilite extraer la esencia misma de la naturaleza humana, sentir que lo humano posee una calidad y singularidad especial, luchar por el bienestar de la humanidad y su amistad con la madre naturaleza. Este sentido de convivencia lo expresa con acierto Jacques Maritain, cuando afirma:

El humanismo es el fenómeno que tiende a hacer al hombre verdaderamente humano y a manifestar su grandeza original haciéndolo participar de todo cuanto puede enriquecerle en la naturaleza y en la historia, concentrando al mundo en el hombre y dilatando al hombre en el mundo. Ello requiere desde luego que el hombre desarrolle las virtualidades en él contenidas; sus fuerzas creadoras, su vida, su razón, a fin de convertir las fuerzas del mundo físico en instrumentos de su propia libertad ${ }^{6}$.

Este tratado no pretende ser un análisis exhaustivo del humanismo grecolatino; pero se recurre a él como obligación reconfortante para argumentar sobre la génesis del humanismo. La cultura grecolatina fue capaz de aportar un legado cultural gracias a su profundo bagaje de conocimientos intervenidos. Los griegos originaron las primeras ideas acerca del pensamiento humanista al construir teorías de carácter ético-filosóficas sobre la naturaleza humana. Las manifestaciones más tempranas del humanismo en textos de la Grecia antigua que han llegado hasta la actualidad están en los poemas de Homero, $L a$ Ilíada y La Odisea, escritos hacia el siglo IX a. n. e. El mundo griego abrió espacios para concretar el lugar que le corresponde ocupar al ser humano en el universo.

Los romanos adoptan las perspectivas del humanismo griego pero dando su propio aporte. Los máximos exponentes del humanismo son los oradores y políticos Cicerón y Seneca. Cicerón antepone el quehacer práctico sobre el saber teórico; Cicerón es uno de los humanistas de mayor relevancia de la Antigüedad.

Mientras tanto, los romanos, influenciados por el helenismo, se destacan en el campo del derecho como uno de los legados más importante de la cultura latina para el

\footnotetext{
4. Miguel Baraona Cockerell y Jaime Mora Arias, Hacia una epistemología del Nuevo Humanismo (San José: EUNED, 2016), 7-8.

5. Ibíd.

6. Molina, Consideraciones generales..., 8 .
} 
ordenamiento jurídico de los Estados. Muchos pensadores romanos continuaron los aportes intelectuales de los griegos, quizás uno de los más representativos fue Cicerón (106 a 43 a.n.e.), filósofo estoico, considerado uno de los humanistas más representativos de la Antigüedad.

Todos estos aportes sobre el humanismo llevan al humanismo de la Edad de Oro islámica, o Renacimiento islámico (siglos VIII-XIII), que viene a dar un soplo a toda la corriente humanista universal. Las conquistas de otros territorios, tanto hacia el Medio Oriente como el norte de África (el Magreb), hasta llegar a la península Ibérica, significó una expansión cultural que nutre a los pueblos conquistados en el arte y en las contribuciones científicas y técnicas.

Históricamente, es en plena Edad Media donde el humanismo estará posesionado por la escolástica. La Iglesia católica es preponderante como institución, pero también es la época del nacimiento de instituciones como las universidades y la banca y es, a la vez, la del florecimiento de las artes, entre otros aspectos.

Durante los siglos XIV, XV y XVI surge el Renacimiento europeo, época muy estudiada y asociada con el humanismo. Se puede decir que el Renacimiento significó una ruptura con la Edad Media, tanto en lo ideológico como en lo cultural; aquí se genera el humanismo renacentista. Giovanni Pico della Mirandola (1463-1494) se destaca para el periodo, muy influenciado precisamente por los trabajos de Averroes y que contribuye a cohesionar el pensamiento humanista europeo.

El humanismo de la Edad Moderna responderá a las directrices y necesidades de acumulación del naciente sistema capitalista. De ahí, las grandes trasformaciones que se manifestarán hasta el siglo XVII, sobre todo en las sociedades europeas en las áreas del arte, la literatura, en los avances científicos-tecnológicos y en el campo sociopolítico y cultural, lo que cambia las relaciones en el seno de la sociedad y en el ámbito de la ciencia y tecnología en Europa. Atrás quedaba un universo que giraba alrededor de una realidad teocéntrica para pasar a una visión antropocéntrica.

Con el paso del siglo XVIII al inicio del XIX, surge dentro del mundo contemporáneo el humanismo liberal como un movimiento político e intelectual en el cual la clase burguesa lucha contra el poder hegemónico de los grupos aristocráticos y oligárquicos que habían dominado por siglos, lucha que se concreta con el triunfo de la Revolución francesa. El liberalismo, como corriente de pensamiento, tiene su asidero durante la Ilustración en el siglo XVIII, abarca a Europa y parte de América y se caracterizó como un movimiento filosófico, político, literario y científico y tecnológico. En el siglo XIX, el humanismo fue uno de los conceptos creados por los historiadores decimonónicos para referirse a la revalorización, la investigación y la interpretación que hicieron algunos escritores desde finales del siglo XIV hasta el primer tercio del siglo XVI sobre los clásicos de la Antigüedad.

Es también en este siglo XIX cuando a la par del humanismo liberal, surge una nueva teoría que se le contrapone. Karl Marx aparece en la escena con su planteamiento del materialismo dialéctico e histórico, que, a pesar del antimarxismo de algunos, continua vigente, lo que en el transcurso de este estudio debe quedar demostrado. Esto, como lo señala Trincado Aznar: 
En la aldea global, es común hablar de la muerte del marxismo y de su correlato científico, el materialismo histórico. Esta situación contrasta con la existente no hace tantos años (década de 1960 y parte del decenio de 1970), cuando hubo, por decirlo de algún modo, un florecimiento del marxismo y del materialismo histórico, y su anuencia en las ciencias sociales era evidente ${ }^{7}$.

Sobran razones para patentizar la importancia del rescate de los principios del humanismo marxista en este estudio a pesar de las inflexiones que se producen en el llamado socialismo de Estado, como aconteció en la antigua Unión de Repúblicas Socialistas Soviéticas. A pesar de esto, el humanismo marxista, tal como lo planteó Marx en sus escritos, posee plena validez bajo los postulados del Nuevo Humanismo que marcan el esfuerzo por dignificar al ser humano en las sociedades del nuevo milenio.

Esta introducción da pie para analizar más ampliamente los diversos humanismos, que surgen en el siglo XIX y que se proyectan y debaten durante el XX, pero destacando la corriente del humanismo marxista.

\section{Antecedentes}

Las ideas primarias sobre el valor humano de igualdad y justicia se pueden ubicar en la Edad Antigua. La sociedad griega del siglo V a.n.e. y la romana entre el siglo XI y I a.n.e., tenían una naturaleza elitista apoyadas en la esclavitud humana, pero exenta de humanismo, puesto que el esclavo era un objeto con valor y uso humano, pero sin humanidad. El humanismo no era una (acción) práctica social. Esta apreciación del humanismo en la historia no se puede evaluar como un calco, sino con entender la cultura del humanismo como dinámica. De gran valor es tomar conciencia de las orientaciones heredadas de la Antigüedad con respecto de la vida moral, artística, política, entre otras, que permitan la formación humanista integral, el educar como lo practicaban las personas en el pasado para que la sociedad humana se revitalice y reivindique constantemente.

El pensamiento filosófico de los griegos, encabezado por Aristóteles, heredaron una idea del humano como identidad espiritual, pensante, parte de una colectividad; este aporte se verá reflejado en el concepto de paideia o educación integral del ser humano. Sin embargo, para fortalecer esta argumentación, se transcribe lo siguiente:

La gran misión de los principales pensadores griegos fue el dar inicio a las teorías de carácter ético-filosóficas sobre la naturaleza humana.

De formas variadas el hombre se encontraba en el centro de todas sus preocupaciones y las distintas dimensiones de su legado cultural dan cuenta de ello (Turner, 1948): en el arte, los griegos establecieron como modelo fundamental para la representación estética la forma humana; en lo religioso, su preocupación primordial fue el alma humana y la relación entre el hombre mortal y los dioses inmortales; en la filosofía, inauguraron la tradición según la cual el instrumento de conocimiento por excelencia es la razón humana; y en la especulación

7. Estrella Trincado Aznar, «Resquicios de materialismo histórico en la historia económica española», Cuadernos de economía, XXXI, Vol. 31, n. 56 (2012), 59-80, acceso: 22 de noviembre, 2019, http://www.redalyc.org/ articulo.oa? $\mathrm{id}=282124593003$ 
científica, por primera vez distinguieron al hombre en cuanto parte de la naturaleza y desarrollaron una filosofía natural coherente con dicho principio. Podría decirse incluso que los griegos fueron los primeros pensadores verdaderamente conscientes de sí mismos: la máxima protagórica de que «el hombre es la medida de todas las cosas» (citada por Platón en Las leyes) refleja el reconocimiento griego del carácter antropológico de todo conocimiento y de que toda obra tiene como efecto la 'humanización' del mundo ${ }^{8}$.

Pero, a pesar de estas contribuciones, lo «humano» se ensombreció en el mundo griego al manejar el humanismo como idea y no como práctica social, debido a una sociedad desigual y fragmentada por clases sociales. Por un lado, una élite que fungía como privilegiada, y por otro, una masa de esclavos o de pueblos bárbaros degradados como seres humanos. Lo que no quita méritos a la influencia y acervo cultural que tuvieron la obra intelectual de Aristóteles, Platón, Heródoto, Protágoras, Esquilo, para mencionar algunos.

Entre los siglos VIII y XIII se desarrolla el humanismo de la Edad de Oro islámica, facilitando una gran contribución al mundo occidental. Ahmed Essa y Othman Ali ${ }^{9}$ recuerdan este aporte, «la brillante contribución del Islam a la ciencia, el arte y la cultura, ofreciendo una visión detallada del gran panorama de erudición que constituyó la base de una visión religioso humanística que daba precedencia al desarrollo intelectual y a la actividad escolástica». La presencia islámica en la península Ibérica (concretamente en el al-Andalus) permite una revolución intelectual con los aportes de pensadores como Avicena y Averroes.

La Edad de Oro islámica se centraliza en plena Edad Media, sobresale en ella la gran influencia de la Iglesia católica en el campo educativo y religioso, es el mundo bajo la égida de la escolástica, introduciendo un nuevo concepto de humanismo que impone una visión sobre lo humano desde el orden divino.

La Edad Media se inició históricamente a partir del siglo III al XVI d. n. e., con la época de la descomposición del Imperio romano. En el siglo V, el cristianismo domina el mundo occidental, «La Iglesia católica como institución educativa y religiosa preponderante introduce un nuevo concepto de humanismo e impone su visión y tratamiento» ${ }^{10}$. En este escenario surge el pensamiento religioso, entre sus máximos representantes se pueden citar: San Agustín de Hipona (354 d. C.-430 d. C.) y Santo Tomas de Aquino (1225-1274), considerado el principal representante de la enseñanza escolástica y una de las mayores figuras de la teología sistemática. En el siglo XV se destaca Pico Della Mirandola (1463-1494), quien fue el primero en acuñar el término humanismo y humanista, le dio continuidad a las ideas de Averroes. En el siglo XVI, Erasmo de Rotterdam

8. Juan Javier Saavedra Mayorga, «Las ideas sobre el hombre en la Grecia antigua», Investigación y Reflexión, Revista de la Facultad de Ciencias Económicas XV, 2 (2007): 218, acceso: 20 de noviembre, 2019, http://www. redalyc.org/articulo.oa?id $=90915212 \mathrm{pdf}$

9. Ahmed Essa y Othman Ali, Estudios sobre la civilización islámica: la contribución musulmana al renacimiento (Virginia: The International Institute of Islamic Thought, 2014), edición en PDF, acceso: 23 de noviembre, 2019, https://iiit.org/wp-content/uploads/2018/07/spanish_-_books-in-brief_studies_in_islamic_civilizations_1.pdf

10. Humberto Aguilar Arroyo, La orfandad paradigmática del humanismo y su práctica negada (San José, Ediciones Litografías EM, 2014), 65. 
(1466-1536), Thomas Moro (1478-1535) y Martin Lutero (1483-1546), artífice de la Reforma Protestante.

En este contexto histórico, el pensamiento se afianza bajo una concepción de que «la carne es considerada como pecaminosa: el cuerpo como cárcel del alma» ${ }^{11}$. Esta idea afirma que el valor de lo humano es divino, por lo tanto «el humanismo es concebido como virtud de misericordia y caridad, desde la visión de la práctica social $\rangle^{12}$. Lo interesante en estos cambios es precisamente apreciar que «si el humanismo griego tenía como objetivo educar, el objetivo del romano era civilizar o romanizar y el del medievo cristiano era evangelizar o cristianizar» ${ }^{13}$. Esta visión del mundo, que afirma que el valor de lo humano es divino, es lo que origina una posición antihumanista, el humanismo no puede ser para posterior de la muerte, puesto que el ser humano posee dignidad en su vida terrenal. El humanismo es una concepción que impulsa a la libertad y al progreso humano con total independencia de la nación, creencia religiosa o diferenciación étnica. El humanismo descarta cualquier demanda a lo sobrenatural.

Los clérigos en la Edad Media asumen la tarea de humanizar, como sinónimo de evangelizar, bautizar e instruir mediante la penetración a los territorios apenas poblados. En estos acomodos emergen las universidades y con ellas la escolástica que se despliega en el mundo intelectual como un saber. El latín fue la lengua de las universidades, ya quedaran en Bolonia, París, Oxford, Colonia, Salamanca o Coímbra, porque cuando esas instituciones se crearon aún no existían como lenguas el italiano, el francés, el inglés, el alemán, el español ni el portugués ${ }^{14}$.

La Época Moderna se caracteriza por el predominio de una nueva corriente de pensamiento que pone en el centro de sus preocupaciones al ser humano, en contraposición a corrientes teístas que ponen a dios, o a varios dioses, como centro de interés, el teocentrismo. La mirada cambia, se traslada desde dios hacia el ser humano. Se habla del humanismo. Los humanistas del Renacimiento orientan sus estudios en retomar los conocimientos de la antigua cultura greco-latina, que facilita la noción válida de que el ser humano está dotado de una personalidad creadora, la cual debe estar libre de preocupaciones moralizantes basada en los postulados teológicos.

Este contexto histórico de la Edad Moderna, se enmarca entre la misma Edad Media y la Edad Contemporánea; transcurre entre los siglos XVI y XVIII, con la caída de Constantinopla en 1453, así como el arribo a América en 1492 por parte de los europeos, hasta el triunfo de la Revolución francesa en 1789, cuando el humanismo surge como movimiento que se desarrolla en Europa; esto rompe con las tradiciones escolásticas medievales y exalta las cualidades humanas, con sentido racional de la vida. Es decir, se pone énfasis en la responsabilidad del propio humano para darle sentido a su vida, sin recurrir a la existencia de un mundo trascendental o un dios. Como consecuencia, se considera al ser humano como centro y medida de todas las cosas.

11. Ibíb, 63 .

12. Ibíb.

13. Jacinto Choza Armenta, Historia cultural del humanismo (España, Editorial Thémata, 2009), 63, acceso: 21 de noviembre, 2019, http://www.cervantesvirtual.com/nd/ark:/59851/bmcgf2t7

14. Choza, Historia cultural..., 64-65. 
En el devenir de la historia, la corriente del humanismo se profundiza en el pensamiento universal y se puede decir que evoluciona en su propia definición. Así, en el Renacimiento hay una nueva visión de humanismo, se origina una ruptura con la Edad Media, en Italia se produce una aceleración histórica, los acontecimientos toman un ritmo precipitado, lo que provoca transformaciones radicales en el orden político y espiritual. El humanismo como movimiento bien definido se forma en el humanismo moderno, donde la ideología de las clases burguesas lucha contra el feudalismo y las concepciones teológicas del medioevo. Los humanistas proclaman la libertad del ser humano, se manifestaban por la defensa del humano a disfrutar del placer y la satisfacción de sus necesidades terrenales. Precisamente los grandes humanistas del Renacimiento, Dante, Petrarca, Bocaccio, Leonardo Da Vinci, Rebelais, Copérnico, Shakespeare y Francis Bacon, contribuyeron en gran medida a que se formara una concepción no religiosa del mundo. Es el momento donde, según Choza:

el humanismo se consideraba como el cultivo de lo humano mediante el estudio de las humanidades, de las letras, porque en la antigüedad clásica, en el renacimiento y en la edad moderna, se concebía la excelencia humana en términos de cultivo del espíritu mediante la actividad intelectual y política como acción propia del hombre ${ }^{15}$.

En este escenario, se provocan cambios espirituales, por ejemplo, la Reforma Protestante (luteranismo, calvinismo, anglicanismo), la contrarreforma católica, la Ilustración y la Revolución francesa. La modernidad, de esencia europea, adquirirá dimensión mundialista, el surgimiento del mercantilismo permitirá la configuración de la sociedad capitalista que sustentará al Estado Moderno. A partir de los últimos cincuenta años del siglo XVIII, y al lado de la Revolución francesa, nace la Revolución Industrial que introduce la máquina de vapor, que facilita los cimientos para crear las bases de la producción en serie o en masa y la aparición de los trabajadores asalariados, consolidando dos sujetos históricos antagónicos: el proletariado y la burguesía.

Durante el siglo XVII, pero sobre todo durante el siglo XVIII, nace el humanismo liberal como un movimiento político e intelectual. Esta corriente de pensamiento, conocida como la Ilustración, emerge como un movimiento social e intelectual europeo centrado en Francia e Inglaterra, donde se desarrolla desde fines del siglo XVII hasta la Revolución francesa de 1798 y, para algunos, hasta el siglo XIX. El humanismo liberal se interpreta como el surgimiento de una concepción del ser humano basado en principios del pensamiento liberal como la universalización de los derechos políticos, sociales y culturales, esto se plasma en la Declaración Universal de los Derechos Humanos bajo los principios de libertad e igualdad. Esta corriente liberal, formulada durante la Ilustración, representó un movimiento social e intelectual que contribuyó a sentar las bases del humanismo moderno. Dentro de este movimiento ilustrado destacan: Spinoza, Voltaire, Diderot, Adam Smith, Montesquieu, Locke, Rousseau, Kant y otros.

Después del triunfo de la Revolución francesa se aflora un nuevo periodo para el pensamiento humanista y de la cultura universal. Sobre todo, al «afianzarse los ideales

15. Ibíd, párr. 2 . 
de libertad, igualdad, fraternidad y dignidad humana. Se defiende el derecho de los individuos a desarrollar sin obstáculo alguno, su auténtica naturaleza. Se insiste en la tolerancia religiosa y en la libertad el pensamiento científico y filosófico» ${ }^{16}$.

Kant plantea su idealismo trascendental al realizar una crítica a la razón, reconoce las categorías de la sensibilidad y del entendimiento. Es pasiva, como la capacidad de recibir impresiones y el entendimiento; es activa, como la capacidad de juzgar y pensar, aplicables a la experiencia, no más allá, como pretendía el racionalismo y el empirismo; y la experiencia vista como el conocimiento teórico. Kant, desde lo sociocultural, defiende la libertad de pensamiento y estructura, una teoría que defienda el valor universal de la razón, para así darle un justo valor a la experiencia. El uso de la razón daba un instrumento a las personas para comprender el mundo y luchar por hacerlo mejor.

Kant junto con Rousseau dieron gran importancia a la educación. Kant defendió la libertad de pensamiento académico contra la imposición de los poderes políticos y religiosos, sostiene como tesis pedagógica fundamental que la educación es absolutamente indispensable para el desarrollo de la humanidad. Mientras tanto, Rousseau desarrolla una corriente en el ámbito del naturalismo educativo, el gran principio de Rousseau es el de que la educación debe ponerse al servicio de la naturaleza humana.

Las diversas lecturas sobre el humanismo parecen llevar a engrandecer al ser humano (antropocentrismo) y afianzar su dignidad en oposición a la perspectiva desvalorativa que se impulsó en el medioevo cristiano. Sin embargo, todos apuntan a ver al humano en su creatividad, en la capacidad de transformar el mundo y construir su propio destino. Pero con la aparición de la burguesía surge un humanismo apegado a la idea de ubicar al humano y su individualidad como fin en sí mismo, considerando al humano como un ser abstracto, al individuo aislado e independiente de las relaciones sociales.

La Revolución Industrial significó un amplio progreso de la economía europea al impulsar la producción manufacturera y de bienes puestos a disposición de la población. Pero también trajo problemas sociales al darse diferencias de oportunidades entre las clases sociales, ante todo de la burguesía y los obreros o proletarios. Esta situación venía a exacerbar las contradicciones en un mundo donde el humanismo liberal surgía en parte de la sociedad europea. Es el momento de la aparición de rebeldía contra el orden establecido. La impronta de las ideas socialistas utópicas surge en la búsqueda de un nuevo orden social, alejado de las injusticias.

Ese primer intento corresponde a Graco Babeuf (1760-1795), republicano y comunista, partícipe de la Revolución francesa, quien muere en la guillotina. En 1795, Babeuf no solo expone su modelo de nueva sociedad sino que, además, encabeza la «conspiración de los iguales» contra el ala más reaccionaria del Directorio. Para algunos, Babeuf fue uno de los principales precursores de la izquierda contemporánea. Esta corriente socialista utópica tuvo como representantes, a la vez, al conde de Saint-Simón (17601825), quien es considerado por algunos como el padre del socialismo francés, mientras Friedrich Engels lo sitúa como precursor del socialismo; a este grupo hay que agregarle a

16. Molina, Consideraciones generales..., 10-11. 
François Fourier (1772-1837) y a Robert Owen (1771-1858). Muchos de los proyectos de estos socialistas utópicos fracasaron, sin embargo sirvieron para nutrir otras corrientes socialistas-humanistas como la marxista.

\section{Humanismo marxista}

Las enseñanzas del socialismo utópico serán recogidas por Karl Marx (1818-1883) y Engels (1820-1895) bajo la propuesta científica y filosófica de la praxis y la concepción materialista de la historia, que venía a revolucionar el discurso del humanismo al plantear por primera vez que las relaciones de producción capitalista representan un antihumanismo, puesto que enajena a la persona.

A partir del marxismo original de Marx y Engels, se desarrollan variedades filosóficas y de acción política del marxismo que, de alguna manera, producen modificaciones en sus interpretaciones. Esta nueva propuesta será recogida y llevada a la práctica por medio de la creación de organizaciones revolucionarias, de trabajadores y de partidos políticos comunistas y socialistas a nivel internacional. En este escenario se destacan teóricos revolucionarios como Antonio Gramsci (1891-1937), León Trotsky (1879- 1940), Mao Zedong (1893-1976) y el peruano José Carlos Mariátegui (1894-1930).

El marxismo ha dado aportes importantes a la sociedad, sea en lo teórico o en la praxis. Gramsci describió el marxismo como una visión del mundo, por ello veía el materialismo histórico no solo como una simple interpretación histórica, sino como una concepción del mundo en su totalidad. Exigía un marxismo alejado de todo positivismo, con una visión antropológica en la cual el factor central no es lo económico, sino ubicar al ser humano. Gramsci vio con claridad que el marxismo es la acción de un humanismo en la historia; así, la historia se hace dialéctica. Gramsci fue un intelectual sólido que planteó sus inquietudes desde el campo educativo, organiza la escuela única de cultura general, humanística, que permita la capacidad de trabajar en forma manual y también en el desarrollo del trabajo intelectual.

Trotsky propone con fuerza la dialéctica, defiende el materialismo dialéctico, al igual que Lenin, el materialismo histórico que visualiza como continuador del dialéctico. Siguiendo esta misma dirección, sobre todo de Lenin, Mao Tsé Tung (o Mao Zedong) concreta su lucha con el triunfo revolucionario de 1949. En su pensamiento, Mao reinterpretó la dialéctica, aportando a la teoría marxista un nuevo modo de entender la praxis y el perfeccionamiento de lo humano.

El paradigma marxista llega de Europa a América Latina, donde será aceptado por intelectuales y la clase obrera. La teoría marxista, y posteriormente la marxista leninista, asume un gran protagonismo al abrir espacios a movimientos revolucionarios que incluso toman el poder político. En este contexto, Mariátegui jugó un papel destacado a principios del siglo XX. Contribuyó para adaptar el paradigma marxista a la realidad social latinoamericana. Mariátegui da un paso trascendental al procurar espacios a nuevos actores sociales: el campesinado y los pueblos indígenas, capaces, junto con otros sectores, de impulsar cambios revolucionarios de carácter socialista. 
Las propuestas de Marx y el marxismo se convirtieron en un poderoso instrumento intelectual y cultural de transformación social, económica y política, una corriente de pensamiento que movió las bases de la sociedad capitalista. Motivó, también, el pensamiento pedagógico de Marx y el marxismo. La temática pedagógica se encuentra en las obras de Marx, que permiten la reconstrucción en el campo de la teoría y la praxis educativa, la educación entendida como educación social, tesis central de su pensamiento.

A partir de la Revolución rusa de Octubre de 1917, Lenin (1870-1924) es el primero en poner en práctica las teorías pedagógicas marxianas en la Unión de Repúblicas Socialista Soviéticas (URSS). De esta manera, irrumpe en el escenario educativo Makarenko (18881939), quien se identifica con la revolución, impulsa en la escuela el carácter colectivista y productivo. Makarenko consideró, desde esta propuesta, que el niño solamente puede ser feliz en un ambiente social donde pueda afirmar sus iniciativas y su espíritu de sociabilidad. Su experiencia quedó plasmada en su extraordinaria obra, Poema Pedagógico.

Junto con Makarenko, en el campo pedagógico de la URSS, se destaca Visil Sujomlinski, que desarrolló una pedagogía del amor: «Escuela de la Alegría», orientada a las personas en edad infantil que han experimentado los horrores de la guerra. Para enseñarles, hay que amarles; solo entonces, quien enseña puede educar en las personas infantiles el sentimiento de alegría por el trabajo, de la amistad, del humanitarismo.

Por otro lado, no se pueden olvidar los aportes de los rusos Vladímir Ivánovich Vernadski (1863-1945), en la teoría de la noosferología, y Víktor Borisovich Shklovsky (1893-1984). El primero trabajó en la articulación de las ciencias geológicas y las ciencias sobre los átomos, logró desarrollar la doctrina de la noosfera y fue uno de los fundadores de la mineralogía genética y la radio geología, extendiendo su trabajo al campo de la cristalografía y la edafología, además en la historia y la metodología de las ciencias naturales. En su trabajo científico mantuvo posiciones del materialismo y de las ideas de la dialéctica. Consideró el pensamiento científico como instrumento para lograr lo nuevo. En el caso de Borisovich Shklovsky, desarrolló el «extrañamiento» en la literatura, donde fija que el propósito del arte es impartir la sensación de las cosas como percibidas y como sabidas o concebidas. Implementó el entendimiento de la actividad literaria como parte integral de la práctica social.

Durante el transcurso del siglo XIX se producen cambios significativos en los planteamientos teóricos dentro del humanismo, orientados a reforzar la presencia del ser humano, «los hombres crean la historia» decía Marx, en referencia a un individuo social, incapaz de vivir fuera de la sociedad. Marx parte del concepto de humano bajo la concepción dialéctica de la realidad, entendiendo a esta como la interacción del ser humano con la naturaleza, humano-social que refleja su propia esencia. Es significativo recordar que el legado fundamental del siglo XIX fue la razón científica, conjuntamente con el ideal del humano como sujeto protagónico de su historia. Así nace el humanismo marxista inspirado en las posiciones de los estudios de Marx. Este humanismo parte de la comprensión del ser humano concreto, lo considera como un ser transformador y portador de un sistema de relaciones sociales y bienes materiales. Este concepto de ser humano en Marx parte de su concepción dialéctica de la realidad y, este compartir con la realidad, es lo que facilita la relación social o humana con esa realidad. Esta simbiosis 
humano-realidad transforma su naturaleza, creando un mundo humano y social que expresa su propia esencia.

Marx logró convertir al humanismo en una concepción científica, posibilitando el paso de un ser humano abstracto a uno real y, en este sentido, se recalcan algunas categorías que han sido fundamentales para entender las relaciones sociales y económicas dentro de las posiciones humanas, haciendo referencia a la categoría de «igualdad» $\mathbf{y}$ de «alienación». La primera permite entender cómo Marx convierte al humanismo en una concepción científica que posibilitó el paso del ser humano abstracto a ser actor social. La segunda, «enajenación» en lo económico, social, político, religioso, etc., en una sociedad dividida en clases donde son los capitalistas los que se apropian del producto del trabajo asalariado de los trabajadores.

Estos conceptos tienen diferentes apreciaciones:

el concepto de alienación en Marx es diferente al concepto de alienación en Hegel y en Feuerbach. Hegel advertía que la alienación es el momento dialéctico de la escisión entre el sujeto y la substancia. En Hegel, la alienación es la «extrañación». De todas formas, la extrañación sería un ser extraño a sí mismo. En Marx, en cambio, la alienación marcará las situaciones en las cuales el hombre se ha perdido a sí mismo. La perdición del hombre se ha producido, sobre todo, en el trabajo realizado por este hombre: lo que produce no le corresponde. En Feuerbach, el sujeto alienado es el hombre y su conciencia, que han sido alienados por la religión y el Dios que ha producido dicha creencia ${ }^{17}$.

Marx refuta esta posición espiritual de Feuerbach, al aclarar que la alienación de carácter religioso está relacionada con la enajenación económica y social; agrega que para entender sus causas, hay que analizar las relaciones económicas y sociales, que son las que sostienen la vida en la sociedad.

Se sostiene que el humanismo marxista es un humanismo radical; lo que significa que las grandes trasformaciones de la realidad son el producto del humano para superar el dominio físico e intelectual que le impone el capitalismo. Hegel no observa esta situación, para él todo ocurre en la idea, en la razón, lo que reduce la realidad social, la praxis histórica que encierra la vida misma del ser humano. En la ideología alemana, Marx no solamente critica el materialismo abstracto de Feuerbach, sino que critica también a Hegel y a todos los filósofos idealistas, quienes toman las contradicciones aparentes y tratan de darles soluciones especulativas con pretensiones de realidad ${ }^{18}$.

Esta pugna ideológica contra las posiciones idealistas (espirituales) fortaleció la concepción materialista de la historia, unido también a los cambios que se producen en el siglo XVIII con respecto a la percepción de la historia universal, con enfoques en una historia política o de los grandes jefes de Estado, a una historia de masas, es decir, una historia social.

17. José Humberto Flores M., «La vigencia del marxismo», Revista Teoría y Praxis, n. ${ }^{\circ} 11$ (2007), 25, acceso: 22 de noviembre, 2019, http://201.131.110.78/jspui/handle/10972/901pdf

18. Ibíd, 27. 
La historia social aparecía, tras la proclamación ideal y solemne de la igualdad de todos los hombres, como la historia de los escándalos de la razón. Como historia de los oprimidos, de los alienados y de los desgraciados. Aparecía también como historia de la queja, (...) Y no necesaria ni principalmente como herramienta política de los socialismos utópicos ni del Manifiesto Comunista de 1848, sino como forma cada vez más viva de la conciencia común del siglo XIX ${ }^{19}$.

El sueño humanista marxista de la creación de un ser humano nuevo con capacidad de construir un mundo «igualitario», de justicia social, en el cual el individuo fuera el actor social de su propio destino, pareció que se materializaba con el triunfo de la Revolución bolchevique dirigida por Lenin en la antigua Rusia. Después de finalizada la Segunda Guerra Mundial y al afianzarse las posiciones dictatoriales de Stalin, el humanismo marxista se desviaba de sus planteamientos originales. La crisis devino en desvíos antihumanistas. Sin embargo, en los años que siguieron después de la guerra, surgió un grupo de filósofos con nuevos planteamientos sobre el humanismo, entre ellos Ernst Bloch, Adam Shaff, Roger Garaudy, Rodolfo Mondolfo, Erich Fromm y Herbert Marcuse, quienes se dieron a la tarea de recuperar y desarrollar aspectos del humanismo presentes en el planteamiento original del marxismo.

Estos filósofos trataron de reinterpretar el pensamiento de Marx bajo una óptica de que no necesariamente fuera lo económico y lo materialista; se dieron a la tarea de la revisión de diversos escritos de Marx, incluyendo, por supuesto, El Capital. A su vez, estos filósofos marxistas trataron de recobrar los aspectos humanistas del pensamiento de Marx, sobre todo en sus escritos de su juventud, lo cual permitió desplegar una interpretación del rol del humano en la sociedad. En sus Manuscritos, Marx lo señala con más claridad, cuando indica que:

(...) el hombre no es solamente un ser natural; es también un ser natural humano, o sea un ser que es para sí mismo y luego un ser que pertenece a una especie; como tal él debe realizarse y confirmarse tanto en su ser como en su saber. Por ello los objetos humanos no son los objetos naturales como se presentan en modo inmediato ${ }^{20}$.

En esta cita, Marx reafirma la posición que juega el humano dentro de la sociedad como agente transformador de realidades y de su propia realidad. Por ejemplo, Mondolfo explica que:

En realidad, si examinamos sin prejuicios el materialismo histórico, tal como nos resulta en los textos de Marx y Engels, debemos reconocer que no se trata de un materialismo, sino de un verdadero humanismo, que en el centro de cada consideración y discusión coloca el concepto del hombre. Es un humanismo realista (Reale Humanismus), como lo llamaron los mismos creadores, el cual trata de considerar al hombre en su realidad efectiva y concreta. Trata de comprender su existencia en la historia y de comprender a la historia como una realidad producida por el hombre a través de su actividad, de su trabajo, de su acción social, durante los siglos en los cuales se va desarrollando el proceso de formación y de transformación del ambiente en el que el hombre vive, y en el que se va desarrollando el hombre mismo $(\ldots)^{21}$.

19. Choza, Historia cultural..., 36 .

20. Salvatore Puledda, Interpretaciones del humanismo (México: Plaza y Valdés, 1996), 29, acceso: 20 de noviembre, 20019, http://elpuente.devallecas.org/uploads/documentos/biblioteca/interpretacioneshumanismo.pdf

21. Ibíd..., 33. 
La perspectiva de Mondolfo señala que el humanismo, en su sentido amplio, valora al ser humano en su condición humana, totalmente vinculado con el aspecto de la generosidad y su preocupación por valorar las cualidades intrínsecas en las relaciones humanas, repensando que el humanismo es un referente de posiciones filosóficas y posiciones éticas que orientan, con énfasis tanto en el valor como en las acciones individuales o colectivas de los humanos.

Es así como Marx ve como fin último la libertad humana; por esto coloca al ser humano en el centro de la naturaleza misma y de la historia. Marx lo profundiza al indicar que:

(...) el hombre que recorre el largo camino de la historia es una criatura mutilada, expropiada de su verdadera esencia: el trabajo social y solidario para humanizar la naturaleza. Porque el hombre es señor y dios, es el centro de la naturaleza. Pero esta historia de lágrimas y sangre, de extrañamiento y dominio, que es la historia de la humanidad, llegará a un término: al final de la Historia, la sociedad ideal, el reino de la libertad —el comunismo - sanará todas las laceraciones, reconciliando al hombre consigo mismo, con los otros hombres y con la naturaleza ${ }^{22}$.

Tiempo después, Fromm hablaba precisamente de un proyecto, de una ciencia del ser humano, asumido en parte por el marxismo como humanismo. Esto lleva a Fromm a la posición de un humanismo radical dentro del marxismo, tratando de llegar más lejos de donde lo logró Marx dentro de la reflexión filosófico-antropológica. Fromm llega a tener una gran influencia de la obra de Marx y lo expresa cuando asegura que:

Lo que más me atraía era su filosofía y su visión del socialismo que expresaba de modo secular la idea de convertirse en uno mismo, del ser humano, de su completa humanización, de aquel ser humano para el cual la meta no es el tener, lo muerto, lo acumulado, sino la propia expresión viva... en realidad la transformación económica era solo un medio para un fin; lo que Marx le importaba decisivamente era la liberación de hombre en el sentido del humanismo ${ }^{23}$.

La pérdida del humanismo marxista, como consecuencia de una serie de acontecimientos que se producen en la Europa de posguerra (la situación creada en la antigua URSS con el estalinismo, el levantamiento popular en Hungría y la construcción del Muro en Berlín), obliga a Ernst Bloch a aprender su reconocimiento de que la historia debe mantenerse hacia aquel «humanismo real» que había sido formulado más de un siglo antes por Marx como el «imperativo categórico de echar por tierra todas las relaciones en que el hombre sea un ser humillado, sojuzgado, abandonado y despreciable» ${ }^{24}$. A pesar de los cambios que se dan en los enfoques desviados del pensamiento marxista, Bloch se posiciona y defiende el auténtico humanismo desarrollado por Marx.

Roger Garaudy toma también posición sobre el humanismo del siglo XX, en este sentido sus aportaciones teóricas son valiosas. El humanismo garaudiano destaca lo siguiente:

22. Ibíd..., 35 .

23. Herder Quitmann, «Psicología Humanística» (citado por Pareja Jiménez, La concepción antropológica de Erich Fromm y sus aportes para el humanismo crítico (2015), 59, acceso: 23 de noviembre, 2019, http://bibliotecadigital.usb.edu.co/bitstream/10819/3895/3/Concepcion_Antropologica_ErichFromm_Pareja_2015.pdf, 59

24. Virgilio Ruiz Rodríguez, «Derechos humanos y deberes», En-claves del pensamiento, año V, núm. 10 (juliodiciembre 2011), 62, acceso: 22 de noviembre, 2019, http://www.redalyc.org/articulo.oa?id=141121432006,pdf 
El trabajo del hombre liberado del capital, es decir, de la alienación, la libertad de los pueblos, en consecuencia, no sometidos a potencia alguna y lucha contra toda guerra que se ampara al átomo, lo cual implica la destrucción de la humanidad. Esta posición del humanismo marxista de Garaudy descansa en la idea de un comunismo en que los hombres sean dueños de sus fuerzas y de trabajo social como seres libres. Este planteamiento es inspirado en las tesis marxistas que están en constante lucha contra la alienación del hombre, por eso bajo los principios marxistas de Garaudy palpamos la idea «del hombre total», optimista con la historia, el que precisamente desarrolla en forma creativa la transformación del mundo ${ }^{25}$.

Garaudy defendió los principios de Marx, aceptó la estrecha relación que debe existir entre la teoría y la praxis y el carácter humanista del materialismo dialectico e histórico. De ahí la idea de ser humano total que debe contribuir a la transformación del mundo.

Bermudo realiza un análisis bastante interesante sobre la crisis del humanismo posterior a 1950:

En la segunda mitad del siglo XX el debate filosófico sobre el humanismo centra la mejor producción filosófica. Se trata de medio siglo en que la filosofía, fuertemente influenciada por las guerras mundiales y las metamorfosis del capitalismo, reabre de forma radical y definitiva el proceso a la ontología subjetivista que fundaba el humanismo. Se comienza, en los años 50, con el asalto heideggeriano: su idea de hombre como Dasein implica el rechazo de la concepción moderna de esencia humana como autonomía, conciencia y voluntad, que pasan a ser vistas como rostros de la técnica y del dominio. En los 60, la opción antihumanista se consolida en los textos de Michel Foucault y Louis Althusser, inspirados en la etnología de Claude Lévy-Strauss, que apuestan con fuerza para reducir la subjetividad a las estructuras duras, económicas, políticas, epistemológicas $(\ldots)^{26}$.

Sin embargo, dentro de este contexto, las posiciones anti humanistas salen a relucir por parte de algunos filósofos enmarcados dentro de la corriente marxista estructuralista que se impuso a mediados de la década de los sesenta del siglo XX, como fue el caso del filósofo e historiador Louis Althusser. Althusser fue un profesor de filosofía, considerado como uno de los principales representantes del Partido Comunista Francés. Recapacitó sobre la necesidad de releer los escritos de Marx y fue un convencido de luchar contra el capitalismo para lograr, a través de la lucha política militante, transformar la realidad social.

Los planteamientos de Althusser están centrados en la necesidad de construir una nueva noción sobre humano y sujeto; así, desde la óptica de un antihumanismo del materialismo histórico, Althusser analiza los escritos de Marx para concluir que los seres humanos no pueden regir a su antojo los destinos de la historia, sino que debe existir el contexto donde priven las condiciones objetivas que en gran medida escapan a su voluntad y a sus deseos subjetivos.

25. Mario German Gil Claros, «La idea de Humanismo en Garaudy, Sartre y Althusser: una polémica», A Parte Rei: Revista de filosofía, n. ${ }^{\circ} 57$ (2008), 11, acceso: 22 de noviembre, 2019, https://serbal.pntic.mec.es/ AParteRei,pdf

26. José Manuel Bermudo Ávila, «Sartre o el humanismo impensable», Convivium, Revista de Filosofía, n. ${ }^{\circ}$ 17 (2004), 121-148), acceso: 23 de noviembre, 1019, https://www.raco.cat/index.php/Convivium/article/ download/73222/98851pdf 
Bajo la concepción materialista de la historia, Marx sostuvo, en el Dieciocho Brumario de Louis Bonaparte, que los seres humanos hacen su propia historia; pero no la hacen a su libre arbitrio, bajo circunstancias elegidas por sí mismos, sino bajo aquellas circunstancias con las que se encuentran directamente, que existen y les han sido legadas por el pasado. No obstante, dentro de las posturas althusserianas de una historia sin sujeto, desde su visión se considera que los individuos actúan en determinadas formas de existencia histórica de las relaciones sociales de producción y reproducción y bajo estas, no pudiendo ser considerados desde las visiones filosóficas sujetos libres. Es aquí donde desde la filosofía no se puede considerar a los seres humanos como sujetos de la historia, sino en la historia; o sea, los humanos dejan de ser los artífices únicos o exclusivos de la historia.

Quizá lo que se está planteando sea la tesis central de toda la aportación filosófica del pensamiento althusseriano, puesto que él considera que la historia es un proceso sin sujeto ni fines, donde las fuerzas productivas se convierten en el motor de las transformaciones sociales determinadas por la lucha de clases. Para Althusser, la historia no tiene sentido, todos somos sujetos y desde esta posición maneja la tesis de que todos somos marionetas de la historia, de algo que no tiene sentido.

Por otra parte, Althusser incursiona en la ideología, a la cual considera ahistórica porque es eterna, siempre existirá como una relación imaginaria de los sujetos con sus relaciones sociales. A la vez, Althusser habla, desde el análisis de los trabajos de Marx, de una «ruptura epistemológica» entre los trabajos de juventud y los realizados en su madurez. Dentro de su proyecto, Althusser trataba de rescatar el poder y originalidad de la teoría de Marx para el avance del conocimiento científico de la sociedad, como un instrumento orientador de la acción política. Aunque no existan «rupturas» misteriosas en la obra de Marx, de la que hablan algunos escritores, en el caso de Althusser, ciertamente sí hay desarrollo histórico, y es este sencillo punto el que la ideología de la praxis está empeñada en pasar por alto. La praxis es justamente lo que define al ser humano como tal y la transformación de las relaciones sociales en sociedad. De ahí que el humanismo marxista «parta de la comprensión del hombre concreto, donde la transformación de las relaciones sociales constituye la base para la lucha en su posible emancipación. Convirtió al humanismo en una concepción científica y posibilitó el paso del ser humano abstracto al real» ${ }^{27}$.

El antihumanismo de Althusser minimiza el papel de la acción humana en el proceso de la historia. Cuando precisamente Marx consideraba que el humano es el sujeto activo de la historia y no un simple producto de esta; es decir, los humanos son sujetos en la historia y no de la historia y, dependiendo de su acción en esta, puede tener un rumbo diferente. Tanto en Althusser como en Michel Foucault, se niega la acción del sujeto, pues lo sujeta a la historia individual de cada persona, cuando en realidad son sujetos culturales e históricos. Con estas posturas se niega el materialismo histórico que proclama los principios de conciencia histórica y transformación histórica-revolucionaria.

27. Liuba Peña Galbán, et al., "La teoría marxista sobre el humanismo. Perspectivas para el Siglo XXI», Humanidades Médicas: n. ${ }^{\circ} 20$ (2007), párr. 5, acceso: 24 de noviembre, 2019, http://scielo.sld.cu/scielo. php?script=sci_arttext\&pid=S1727-81202007000200006\&lng=es\&tlng=espdf 


\section{Conclusiones}

Se ha tratado de describir un acercamiento al concepto de humanismo y sus diversas interpretaciones, así como a los matices que ha recibido en el transcurso de determinadas épocas históricas. Este proceso evidencia la existencia de diversas corrientes y posturas sobre si existe o no un humanismo real. En este sentido, surge un antihumanismo, sobre todo durante el siglo pasado, el cual origina un profundo debate, como resultado de las grandes guerras mundiales, así como de los avances científicos-tecnológicos. En el campo político-ideológico, influye lo que acontece en la ex Unión de Repúblicas Socialistas Soviéticas, con las actuaciones de Stalin. Estos acontecimientos impulsan a teóricos para que tomen partido con las posturas de Marx y del marxismo, conocido como el movimiento de los «humanistas marxistas», de los cuales se referenció a dos, Fromm y Garaudy. Además, en paralelo surgió una corriente marxista antihumanista, representada por Foucault, Heidegger y Althusser.

Heidegger, en su reflexión, considera que «todo humanismo se basa en una metafísica, excepto cuando se convierte él mismo en el fundamento de tal metafísica» ${ }^{28}$, con esto pretendía recuperar al ser que se ha olvidado en la esencia del humano mismo. Esta postura va en contraposición al humanismo de Marx, quien piensa en el «hombre social» como un ser humano natural que necesita de bienes y de la producción para cubrir sus necesidades económicas, y como un ser transformador de la realidad social. Para Heidegger, el humanismo debe meditar que el humano sea humano, no ajeno a su esencia, por ello valora al humanismo desde la historicidad, puesto que los humanismos desde la Antigüedad parten del conocimiento previo de la esencia de lo humano como premisa fundamental, en lugar de plantearse la pregunta por la esencia de lo humano.

Mientras tanto, para Foucault, uno de los obstáculos que enfrenta el pensamiento actual es la idea de humanismo, al sentir que esta premisa debe ser abandonada. El ser humano es una invención reciente que el saber humano ha elaborado. El humano, sujeto libre y racional, no existe. Aquí se refleja el antihumanismo de Foucault: el humano creado por el discurso del humanismo es ficticio, es subjetividad. Ese «humano» era un objeto constituido por los discursos de la «época clásica», al que los nuevos discursos que parten del siglo XIX se han encargado de destituir.

\section{ABSTRACT}

\section{Marxist humanism}

The main objective of this article is to evaluate the evolutionary process through which humanism has advanced in its historical memory, in addition to demonstrating the paradigmatic leap that developed under the vision of Marxist humanism. A qualitative and historical approach is used to explain three methodological elements of labor: first, to identify the genesis of humanism in the unfolding of nature and the existence of humanity; second, the types of humanism

28. Martin Heidegger, «Carta sobre el Humanismo», traducción de Helena Cortés y Arturo Leyte (Madrid: Alianza Editorial, 2000), 4, acceso: 24 de noviembre, 2019, https://0201.nccdn.net/1_2/000/000/0ce/3c3/Heidegger-Martin.---Carta-sobre-el-Humanismo--2006-.pdf 
according to the historical moment, including movements such as the Enlightenment, the French and German liberal humanisms of the eighteenth century; and third, analysis of Marxist humanism as the emancipatory paradigm of the human being. Marxist humanism is problematized, since Marx poses, for the first time in the history of mankind, how the alienation of the human being is incubated in the social and productive relations of the capitalist system. A hermeneutical analysis was carried out to articulate the historical, cultural, socio-political and contextual dimension of various published studies on the subject, with the intention of demonstrating the contributions of Marx and Marxism to the discourse of humanism.

Key words: History, anti-humanism, society, alienation.

\section{RÉSUMÉ}

\section{L'humanisme marxiste}

Cet article vise à réfléchir sur le processus évolutif par lequel l'humanisme a transité dans son devenir historique. En plus, il a pour but de démontrer le changement de paradigme né sous la vision de l'humanisme marxiste. À travers l'approche qualitative et l'aperçu historique, on explique les trois éléments méthodologiques du travail : d'abord, l'identification de la genèse de l'humanisme dans le déroulement de la nature et l'existence de l'humanité. Ensuite, on identifie aussi les types d'humanisme d'après les moments historiques, sans oublier les mouvements tels que l'Illustration, l'humanisme libéral français et allemand du XVIII ${ }^{\text {ème }}$ siècle. Finalement, l'analyse de l'humanisme marxiste comme paradigme émancipateur de l'être humain. Compte tenu que l'humanisme marxiste, proposé par Marx pour la première fois dans l'histoire de l'humanité, examine comment dans les relations sociales et la production du système capitaliste s'incube l'aliénation de l'être humain, on fait une analyse herméneutique qui articule la dimension historique, culturelle, socio-politique et contextuelle de diverses études publiées sur le sujet, et qui a l'intention de mettre en évidence les apports de Marx et du marxisme au discours de l'humanisme.

Mots-clés: Histoire, antihumanisme, société, aliénation.

\section{Referencias bibliográficas}

Aguilar Arroyo, Humberto. La orfandad paradigmática del humanismo y su práctica negada. San José: Ediciones Litografías EM, 2014.

Ahmed Essa y Othman Ali. Estudios sobre la civilización islámica: la contribución musulmana al renacimiento (Virginia: The International Institute of Islamic Thought, 2014). Edición en PDF. Acceso: 23 de noviembre, 2019, https://iiit.org/wp-content/uploads/2018/07/spanish_-_books-in-brief_studies_in_islamic_civilizations_1.pdf

Baraona Cockerell, Miguel y Jaime Mora Arias. Hacia una epistemología del Nuevo Humanismo. San José: EUNED, 2016.

Bermudo Ávila, José Manuel. «Sartre o el humanismo impensable». Convivium, nº 17 (2004): 121-148. Acceso: 23 de noviembre, 2019, https://www.raco.cat/index.php/Convivium/article/download/73222/98851,pdf

Choza Armenta, Jacinto. Historia cultural del humanismo. España: Editorial Thémata, 2009. Acceso: 21 de noviembre, 2019, http://www.cervantesvirtual.com/nd/ark:/59851/bmcgf2t7

Flores M., José Humberto. «La vigencia del marxismo». Teoría y Praxis (2007): n. ${ }^{\circ} 11$. Acceso: 22 de noviembre, 2019, http://201.131.110.78/jspui/handle/10972/901, pdf

Gil Claros, Mario Germán. «La idea de humanismo en Garaudy, Sartre y Althusser: una polémica». AParte Rei (2008): n. ${ }^{\circ}$ 57. Acceso: 22 de noviembre 2019, https://serbal.pntic.mec.es/AParteRei,pdf 
Heidegger, Martin. Carta sobre el humanismo. Trad. de Helena Cortés y Arturo Leyte. Madrid: Alianza Editorial, 2000. Acceso: 24 de noviembre, 2019, https://0201.nccdn.net/1_2/000/000/0ce/3c3/Heidegger-Martin.---Carta-sobre-el-Humanismo--2006-.pdf

Molina González, Jorge Rolando. «Consideraciones generales sobre diversas concepciones históricas del humanismo». Revista Estudios (1989): n. ${ }^{\circ}$ 8. Acceso: 22 de noviembre 2019, https://dialnet.unirioja.es/ servlet/articulo?codigo $=6135730$

Paredes, Claudia. Introducción al humanismo. Colombia: Universidad Nacional Abierta y a Distancia, 2008. Acceso: 22 de noviembre, 2019, http://datateca.unad.edu.co/contenidos/90016/2013_2/90016_ONLINE/ leccin_pdf

Peña Galbán, Liuba, Magalys Mena Fernández, Jorge Cardoso Hernández y Maritza Placeres Collot. «La teoría marxista sobre el humanismo. Perspectivas para el siglo XX». Revista Humanidades Médicas (2007): n. ${ }^{\circ}$ 20. Acceso: 24 de noviembre, 2019, http://scielo.sld.cu/scielo. php?script=sci_arttext\&pid=S1727-81202007000200006\&lng=es\&tlng=es.

Puledda, Salvatore. Interpretaciones del humanismo. México: Plaza y Valdés Editores, 1996. Acceso: 20 de noviembre, 2019, http://elpuente.devallecas.org/uploads/documentos/biblioteca/interpretacioneshumanismo.pdf

Quitmann, Herder. Psicología humanística. Ed. Herder. Citado por Pareja Jiménez, La concepción antropológica de Erich Fromm y sus aportes para el humanismo crítico (2015). Acceso: 23 de noviembre 2019 , http://bibliotecadigital.usb.edu.co/bitstream/10819/3895/3/Concepcion_Antropologica_ErichFromm_ Pareja_2015.pdf

Ruiz Rodríguez, Virgilio. Derechos Humanos y Deberes. En-claves del pensamiento. Año V, núm. 10 (juliodiciembre, 2011), pág.62. México: Instituto Tecnológico y de Estudios Superiores de Monterrey. Acceso: 22 de noviembre, 2019, http://www.redalyc.org/articulo.oa?id=141121432006.pdf

Rus Rufino, Salvador. «La aparición del humanismo en Grecia y la aportación de Protágoras». Revista de fundamentación de las Instituciones Jurídicas y de Derechos Humanos. 123-161. Acceso: 23 de noviembre, 2019, http://dadun.unav.edu/bitstream/10171/12535/1/PD_13_04.pdf

Saavedra Mayorga, Juan Javier. «Las ideas sobre el hombre en la Grecia antigua». Revista de la Facultad de Ciencias Económicas: Investigación y Reflexión, XV, 2 (diciembre, 2007), 213-234. Acceso: 22 de noviembre, 2019, http://www.redalyc.org/articulo.oa?id=90915212

Trincado Aznar, Estrella. «Resquicios de materialismo histórico en la historia económica española». Cuadernos de economía. XXXI (2012). Bogotá, Colombia. Acceso: 22 de noviembre, 2019, http://www.redalyc. org/articulo.oa?id=282124593003,pdf

Villafañe Serrano, Emilio. Cristianismo y marxismo (1976). Acceso: 22 de noviembre, 2019, https://dialnet. unirioja.es/descarga/articulo/1704476.pdf 